GEOPHYSICAL RESEARCH LETTERS, VOL. 20, NO. 11, PAGES 1011-1014, JUNE 7, 1993

\title{
VARIABILITY OF DAYSIDE CONVECTION AND MOTIONS OF THE CUSP/CLEFT AURORA
}

\author{
M. Lockwood', J. Moen ${ }^{2}$, S.W.H. Cowley ${ }^{3}$, A.D. Farmer ${ }^{4}$, U.P. Løvhaug ${ }^{5}$, H. Lühr ${ }^{6}$ and V.N. Davda ${ }^{1}$
}

\begin{abstract}
We present measurements of the ionospheric plasma flow over the range of invariant latitudes $71-76^{\circ}$, observed at 10 -second resolution using both the EISCAT radars, with simultaneous observations of the $630 \mathrm{~nm}$ cusp/cleft aurora made by a meridian-scanning photometer at $\mathrm{Ny}$ Allesund, Svalbard. A major increase in the trans-auroral voltage from 5 to $40 \mathrm{kV}$ (associated with sunward convection in the early afternoon sector) is found to follow a southward motion of the aurora and coincide with the onset of regular transient auroral breakup events. It is shown that these observations are consistent with recent theoretical work on how ionospheric flows are excited by time-dependent reconnection at the dayside magnetopause.
\end{abstract}

\section{Introduction}

Combined observations by the EISCAT UHF radar and the AMPTE-UKS and -IRM satellites have demonstrated that the dayside convection responds rapidly to southward turnings of the interplanetary magnetic field, IMF (Etemadi et al., 1988; Todd et al., 1988). Detailed analysis of one event by Lockwood et al. (1986) showed that the convection enhancement (detected from the resulting ion temperature rise) moved away from noon at several $\mathrm{km} \mathrm{s}^{-1}$, a conclusion recently supported by Saunders et al. (1992) from a series of events seen by the CANOPUS array of magnetometers.

Such observations have led Cowley and Lockwood (1992) to propose a new model for how reconnection at the dayside magnetopause excites ionospheric flow (see also Lockwood and Cowley, 1992). The onset of reconnection converts closed magnetic flux to open flux: hence in the ionosphere, magnetic flux must cross the open/closed field line boundary in the rest frame of the boundary (at a velocity $\mathbf{v}^{\prime}$ which depends on the reconnection rate). In the Earth's frame, this can be achieved by exciting poleward flow and/or by the boundary moving equatorward. In one limit, the boundary remains static in the Earth's frame $\left(v_{b}=0\right)$, and the onset of reconnection, after an Alfvén wave travel time of roughly 2 min., causes poleward ionospheric flow of velocity (in the

\footnotetext{
${ }^{1}$ Rutherford Appleton Laboratory, Chilton, UK

${ }^{2}$ Department of Physics, University of Oslo, Norway

${ }^{3}$ Blackett Laboratory, Imperial College, London, UK

${ }^{4}$ Atmospheric Physics Laboratory, UCL, London, UK

${ }^{5}$ EISCAT Scientific Association, Ramfjordmoen, Norway

${ }^{6}$ Technische Universität Braunsweig, Germany
}

\section{Copyright 1993 by the American Geophysical Union.}

Earth's frame) $\underline{v}_{p}=\underline{v}^{\prime}$. However, were the boundary to move equatorward (at the same speed as the poleward plasma flow for a static boundary, i.e. the poleward boundary velocity is $\left.v_{b}=-\underline{v}^{\prime}\right)$ then no ionospheric flow is initially excited $\left(v_{p}=0\right)$. In general, $\underline{v}^{\prime}=\underline{v}_{p}-\underline{v}_{b}$. Hence if the reconnection rate subsequently continues to be large, the boundary motion may slow and the poleward flow, $\underline{v}_{p}$ will increase. Alternatively, the reconnection rate may decrease and the boundary relax poleward. In this case also, poleward flow will be excited (even in the limit where $v^{\prime}=0$, when $v_{p}=v_{b}>0$ ).

Observations indicate that the open/closed boundary does indeed migrate southward following a southward turning of the IMF. Burch (1973) observed that the latitude of the cusp/cleft precipitation was statistically lower with increasingly southward IMF. In addition, the dayside aurora was observed to migrate equatorward following southward IMF turnings by Horwitz and Akasofu (1977), as did the cusp/cleft defined from radar data by Foster et al. (1980). Recently, Lockwood and Cowley (1992) showed the dayside ionospheric flow boundary, deduced from a global network of magnetometers, also expands equatorward following a southward turning and that the flows are modulated by the boundary motions in the way discussed above.

Horwitz and Akasofu (1977) also reported polewardmoving auroral transients when the IMF was southward. These have recently been extensively studied from the Svalbard islands using all-sky cameras and meridian-scanning photometers (MSP) which resolve the $557.7 \mathrm{~nm}$ and the 630 nm emissions produced by magnetosheath electron precipitation in the cusp/cleft region (see Sandholt et al., 1992). These "dayside-auroral breakup" events have been found to be associated with bursts of enhanced ionospheric flow (Lockwood et al., 1989) and have been interpreted in terms of variations of the magnetopause reconnection rate. In this paper, we investigate the ionospheric flows which accompany an equatorward motion of the cusp/cleft aurora and the onset of transient dayside break-up events. The results reveal the close association of the auroral motions and forms with the strength of dayside convection and support the theoretical concepts of Cowley and Lockwood (1992).

\section{Observations}

We describe 10-s. ionospheric flow observations made by using both the UHF and VHF EISCAT radars simultaneously in the SP-UK-CONV mode. In addition, 18-s. scans by the $630 \mathrm{~nm}$ MSP at Ny Ålesund are presented. Figure 1 shows a map of the MSP scan relative to the radar beams. In the SP-UK-CONV mode, the UHF radar points magnetically northward at an elevation of $20^{\circ}$, so the poleward flow component, $v_{N}$ is directly observed (to within a small uncertainty of roughly $\pm 100 \mathrm{~m} \mathrm{~s}^{-1}$ introduced by fieldparallel flows). The VHF radar points $15^{\circ}$ to the east of the UHF and at its minimum elevation of $30^{\circ}$. The line-of-sight velocities from the two radars are combined to estimate the 


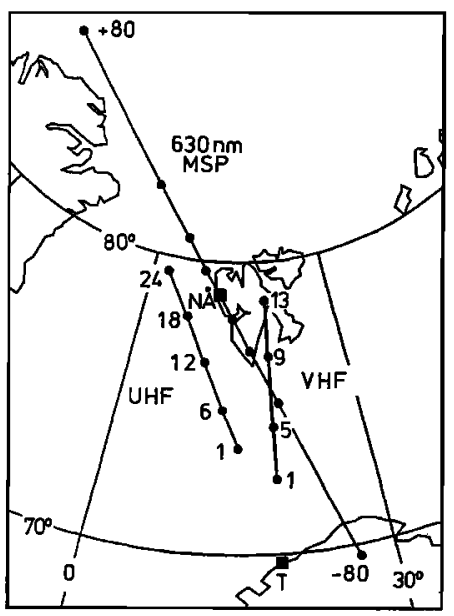

Fig. 1. Map of EISCAT UHF and VHF radar beams for the SP-UK-CONV mode in which signals are transmitted and received at Troms $\varnothing(\mathrm{T})$. The numbered dots denote the range gate centres. Also shown is the meridian scanned by the 630 $\mathrm{nm}$ photometer (MSP) at Ny Ålesund (NÅ), for which dots show the locations for $20^{\circ}$ steps in zenith angle (positive northward) for an emission altitude of $300 \mathrm{~km}$.

westward flow component, $\mathbf{v}_{\mathrm{W}}$. Effectively, it is assumed that the flow is constant along the L-shell over the distance between the beams, $d$, which varies between 110 and 220 $\mathrm{km}$. The voltage across the north/south dimension of the radar field-of-view is estimated from $V_{j}=\Sigma_{j} v_{w} B_{i} d l$, where the sum is over all $j=17$ UHF gates (covering the range of invariant latitudes $\Lambda=71-76^{\circ}$ also observed by the $\mathrm{VHF}), \mathrm{B}_{\mathrm{i}}$ is the local magnetic field and $\mathrm{dl}$ is the distance between the L-shells of adjacent UHF gates $(\approx 35 \mathrm{~km})$.

Figure 2 summarises the observations on 7 January 1992 discussed in this paper. The top panel shows the voltage, $V_{n}$, (corresponding to westward, i.e. sunward, flow) as a function of time. A major increase in this flow was observed between 10:38 and 10:40 UT, when the voltage rose from 5 to $40 \mathrm{kV}$. The flow vectors (not shown) reveal that the flow direction was relatively steady and north-westward. This onset of strong convection is the subject of this paper. The lower panel summaries the results from the MSP. Note that the plot is offset by $110 \mathrm{~s}$. with respect to the upper panel: this is the mean lifetime of the $1 \mathrm{D}_{2}$ to $3 \mathrm{P}$ transitions of the atomic oxygen, i.e. the average delay between excitation of the metastable $1 D_{2}$ state and subsequent emission of a $630 \mathrm{~nm}$ photon. The thin lines show the zenith angles of the poleward and equatorward edges of the $630 \mathrm{~nm}$ emission (between them it exceeded the $0.5 \mathrm{kR}$ threshold adopted). The dashed lines give the locations of relatively stable peaks in the emission and the solid lines show poleward-moving peaks of enhanced intensity, in dayside auroral breakup events. It can be seen that immediately prior to the flow enhancement, the $630 \mathrm{~nm}$ aurora moved equatorward, and that at the time of the enhancement there began a series of dayside breakup transients. Two isolated transients were observed before the equatorward motion, each accompanied by a modest flow enhancement. Comparison with figure 1 shows that at its most southerly zenith angle, the $630 \mathrm{~nm}$ aurora was very close to the poleward limit of the combined radar observations (UHF gate 17 , VHF gate $13, \Lambda=76^{\circ}$ ). The data

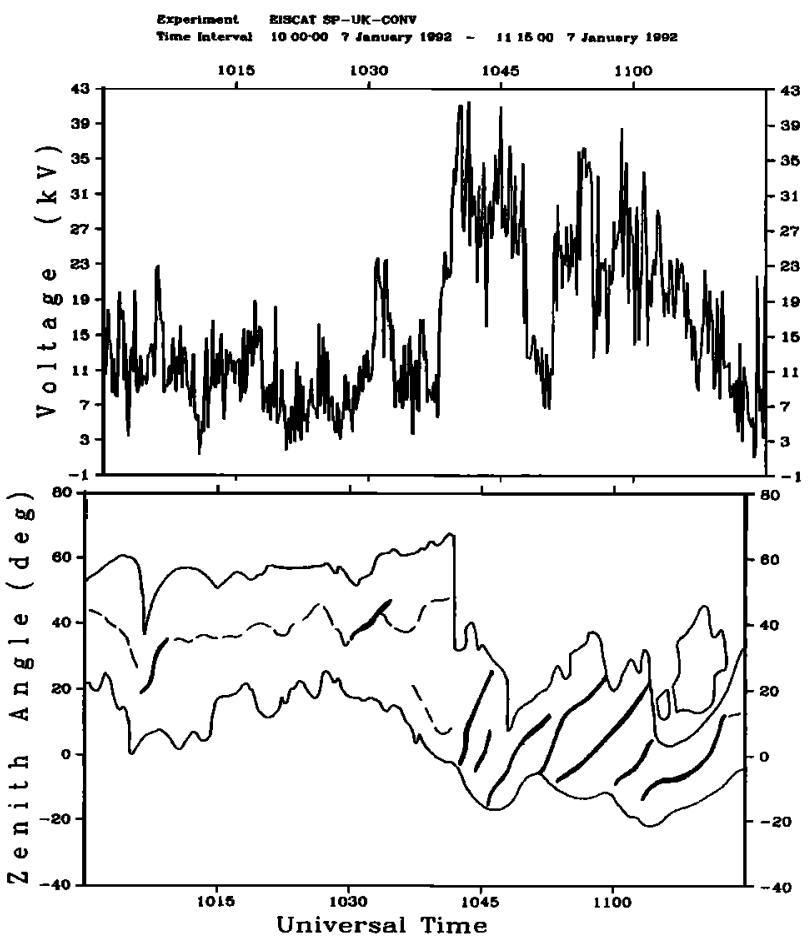

Fig. 2. (a) Voltage, $V_{j}$, across the north/south extent of the radar field of view $\left(71-76^{\circ}\right.$ ) estimated from SP-UK-CONV on 7 January 1992. (b) Summary of the $630 \mathrm{~nm}$ photometer data (see text). The two plots have been offset by $110 \mathrm{~s}$.

from a second MSP reveal that $557.7 \mathrm{~nm}$ emissions were only present during the dayside breakup events.

Figure 3 shows the $630 \mathrm{~nm}$ MSP data around the flow enhancement. It should be remembered that the $630 \mathrm{~nm}$ emissions reveal where $O$ atoms were excited by electron precipitation some time earlier (plus or minus an error introduced by thermospheric winds). For a very few atoms that delay is effectively zero, but on average it is $110 \mathrm{~s}$. By about 10:36, the emissions had clearly become double peaked. The more poleward of these two persisted at about the same zenith angle, until it faded around 10:41. The other peak moved equatorward, reaching a minimum latitude at 10:40. Three transient events were then observed in quick succession, each forming equatorward of its predecessor and then drifting poleward. These events could first be defined at 10:40:15, 10:41:30 and 10:42:45. Figure 4 shows the radar data in greater detail. The top panel shows the voltage increase (as shown in figure 2a). The middle panel shows contours of the northward flow speed, as observed directly by the UHF radar. A string of three enhancements of $\mathbf{v}_{\mathrm{N}}$ was seen poleward of $\Lambda=74^{\circ}$, commencing at about 10:37:00, 10:38:15 and 10:39:30. As with the optical events, the strength of each event increased and the latitude of onset decreased, progressively, and events were $75 \mathrm{~s}$. apart. The bottom panel shows the ion temperatures observed by the two radars at $\Lambda=73.2^{\circ}$. A general rise in ion temperature was seen as the flow increased and the rise for the VHF radar lagged that seen by the UHF radar. The best correlation is for a lag of 30s. which, for the $180 \mathrm{~km}$ separation of the two beams at this L-shell, yields an eastward phase motion of the flow enhancement of $6 \mathrm{~km} \mathrm{~s}^{-1}$. 


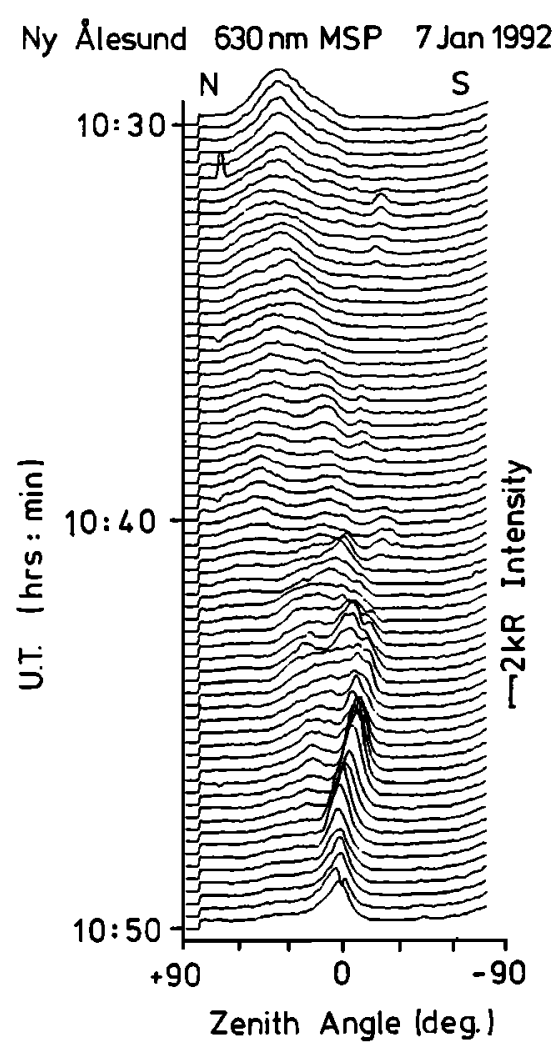

Fig. 3. Photometer scans, showing $630 \mathrm{~nm}$ intensity as a function of zenith angle, for the period 10:30-10:50 UT.

\section{Discussion}

The data shown here reveal three of the characteristics known to follow a southward turning of the IMF: an equatorward migration of the $630 \mathrm{~nm}$ aurora, the onset of regular dayside breakup transients and an increase in the plasma convection. As in the Lockwood et al. (1986) and Saunders (1992) studies, the flow enhancement is seen to propagate away from noon (in this case near 13:30 MLT at a phase speed of $6 \mathrm{~km} \mathrm{~s}^{-1}$ ). Such a phase motion is also inherent in the variation of response time with MLT derived by Etemadi et al. (1988) and Todd et al. (1988). Unfortunately, IMP-8 was in a good position but not tracked during this period and hence we cannot confirm the inferred southward turning of the IMF.

Figure 2 shows that the equatorward motion of the $630 \mathrm{~nm}$ aurora began after the isolated transient at 10:33, whereas the flow voltage and ion temperatures do not increase significantly until after 10:38. In this interval, the equatorward-moving $630 \mathrm{~nm}$ peak moved in zenith angle from $41^{\circ}$ to $12^{\circ}$ which, for an assumed emission altitude of $300 \mathrm{~km}$, is a distance of $200 \mathrm{~km}$ and an average speed of $v_{b}$ $=-670 \mathrm{~m} \mathrm{~s}^{-1}\left(\approx v^{v}\right)$. Figure 3 shows that when this equatorward motion ceased, three poleward-moving transient events formed and we have seen that each was preceded by a localised burst of poleward flow and the general increase in the overall sunward convection.

These results are in excellent agreement with the CowleyLockwood theory of flow excitation discussed in the introduction. This is illustrated by figure 5 , which shows the application of this theory by Cowley et al. (1991). Flow

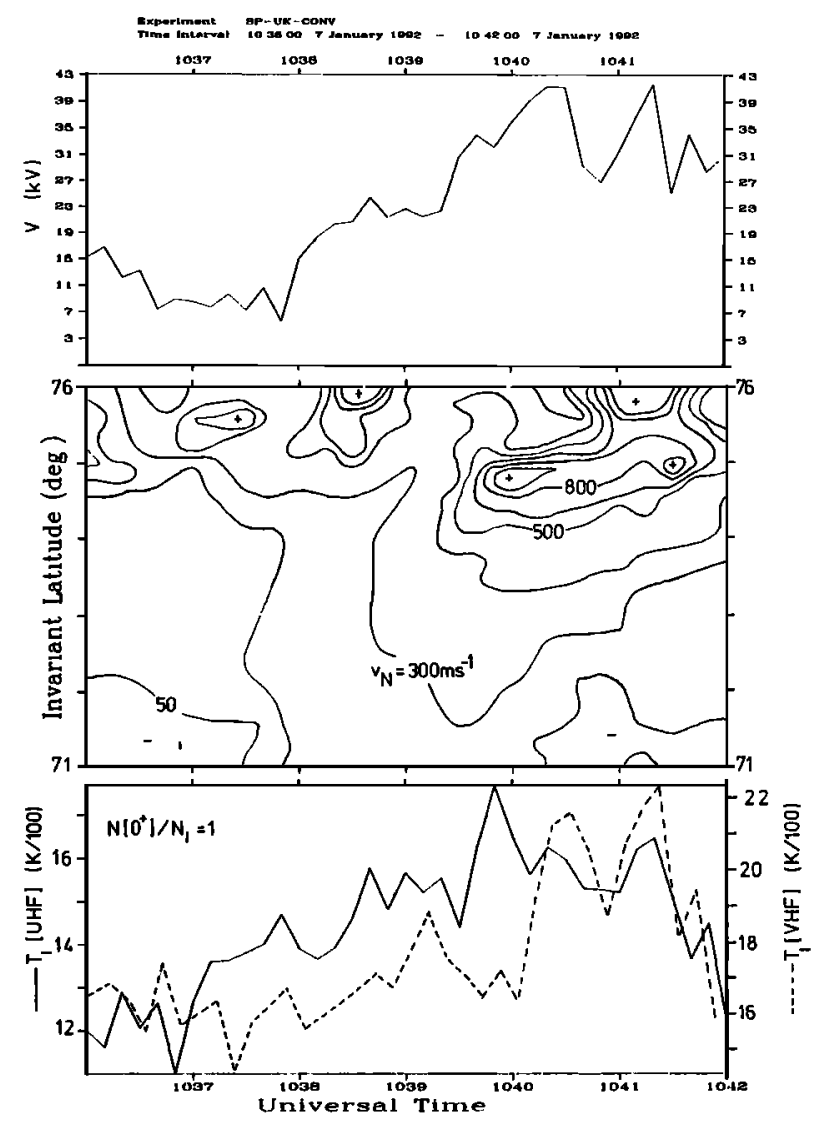

Fig. 4. EISCAT data for 10:32-10:46: (a) the voltage associated with the westward flow; (b) contours of northward flow speed $\left(v_{N}\right)$ observed by the UHF radar; and (c) the ion temperatures observed by both radars at $\Lambda=73.2^{\circ}$.

streamlines are marked with arrows and the position of $\mathrm{Ny}$ Alesund and the MSP scan are shown. The solid lines show non-reconnecting segments of the open/closed boundary ("adiaroic" - i.e. $v^{\prime}=0$ ); the dot-dashed lines map to an active reconnection $\mathrm{X}$-line (i.e. $\mathrm{v}^{\prime} \neq 0$ ) and the dashed line shows the boundary between newly-opened flux produced after the onset of enhanced reconnection and lobe flux which was reconnected at some earlier time. After a delay of 2-3 min. (discussed later), we expect $630 \mathrm{~nm}$ emission on the newly-opened field lines, caused by the precipitating magnetosheath (cusp) electrons. This precipitation will last for some 10-15 min. on any one field line after it is reconnected, as it convects over the dayside magnetopause (Cowley et al., 1991). However, observed intensities are integrated along the slant path and may decrease as events move poleward because of the change in viewing geometry. Between 10:33 and 10:38, the equatorward motion of the boundary (and the $630 \mathrm{~nm}$ aurora) reflects the generation of open flux by enhanced reconnection, presumably due to a southward turning of the IMF. However, no increase in the plasma flow is seen at this time. Instead, the flow is enhanced when the boundary motion slows. Because the changes in the reconnection rate are envisaged to commence near noon, the enhanced convection propagates away from noon. After the two weak bursts (which we interpret as the effects of roughly $1-\mathrm{min}$. variations in reconnection rate), a 


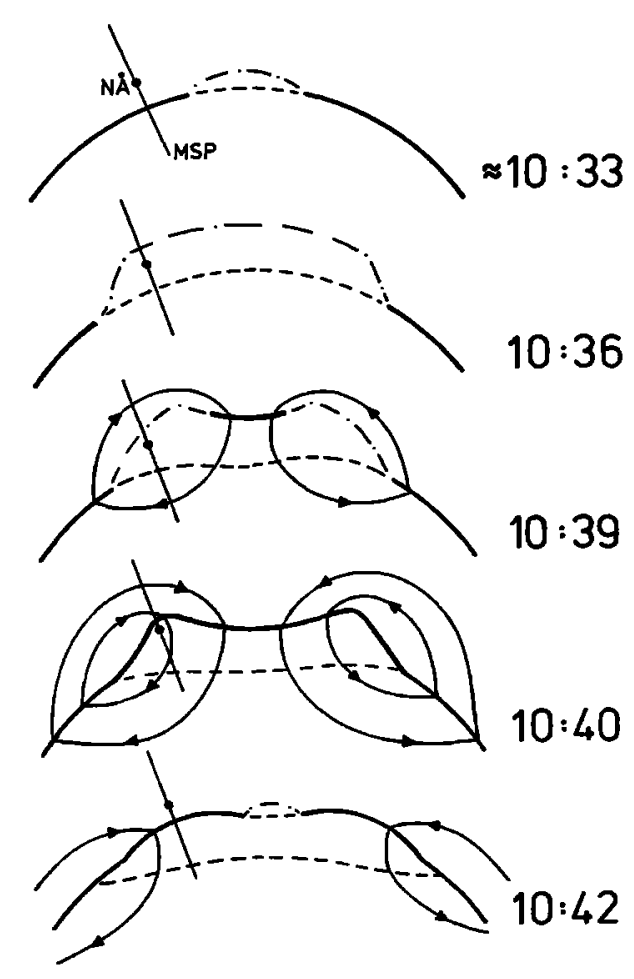

Fig. 5. Schematic of the evolving open/closed boundary and plasma flows. (Adapted from Cowley et al., 1991).

major burst of poleward flow at $v_{p}=1 \mathrm{~km} \mathrm{~s}^{-1}$ is observed after 10:39:30. This is also the speed of poleward phase motion of this flow event and of its associated $630 \mathrm{~nm}$ transient (for the assumed emission altitude of $300 \mathrm{~km}$ ). We conclude that after 10:39:30 the reconnection at the MLT of the observations had ceased so that the boundary returned poleward with the same speed as the poleward plasma flow $\left(v^{\prime}=0, v_{p}=v_{b} \approx 1 \mathrm{~km} \mathrm{~s}^{-1}\right)$.

Figures $4 b$ and 3 reveal the sequences of the $v_{N}$ bursts and the $630 \mathrm{~nm}$ transients to be almost identical, the onsets of latter being lagged by $195 \mathrm{~s}$. For each transient, the peak luminosity was observed at least 100 sec. after onset, which we attribute to the mean radiative lifetime of the excited $1 D_{2}$ state. The lag in the onsets is not due to this lifetime. We suggest that the delay before onset of the optical events is due to the time-of-flight of cusp ions, which causes low fluxes of the electrons responsible for the $630 \mathrm{~nm}$ emission on the most recently-reconnected field lines, such that the observed quasi-neutrality of the cusp is maintained (Burch, 1985). Onset of each event then reflects the arrival of sufficient fluxes of ions and electrons, after the arrival of the Alfvén wave associated with the momentum transfer.

Lastly, we note that IMF $\left|B_{y}\right|$ must have been small; otherwise the 'tension' force on the newly-opened flux would have produced large zonal flow bursts, without the $5 \mathrm{~min}$. delay, as observed by Lockwood et al. (1989).

Acknowledgements. We thank the Director and staff of the EISCAT Scientific Association. These observations were made as part of a GEM boundary-layer campaign.

\section{References}

Burch, J.L. Rate of erosion of dayside magnetic flux based on a quantitative study of polar cusp latitude on the interplanetary magnetic field, Radio Sci., 8, 955, 1973.

Burch, J. L., Quasi-neutrality in the polar cusp, Geophys. Res. Lett., 12, 469, 1985.

Cowley, S.W.H. and M. Lockwood, Excitation and decay of solar-wind driven flows in the magnetosphere-ionosphere system, Annales Geophys., 10, 103, 1992.

Cowley, S.W.H., et al., The ionospheric signature of flux transfer events, in "CLUSTER - dayside polar cusp", ESA $S P-330$, pp 105-112, Nordvijk, The Netherlands, 1991.

Etemadi, A., et al., The dependence of high-latitude dayside ionospheric flows on the north-south component of the IMF: a high time resolution correlation analysis using EISCAT "POLAR" and AMPTE UKS and IRM data Planet. Space Sci., 36, 471, 1988.

Foster, J.C., et al., Radar observations of cleft dynamics, $J$. Geophys. Res., 85, 3453, 1980.

Horwitz, J.L. and S.-I. Akasofu, The response of the day-side aurora to sharp northward and southward transitions of the interplanetary magnetic field and to magnetospheric substorms, J. Geophys. Res., 82, 2723-2734, 1977.

Lockwood, M. and S.W.H. Cowley, Ionospheric convection and the substorm cycle, in "Substorms 1", ESA-SP 335, pp. 99-109, Nordvijk, The Netherlands, 1992.

Lockwood, M., et al., Eastward propagation of a plasma convection enhancement following a southward turning of the IMF, Geophys. Res. Lett., 13, 72, 1986.

Lockwood, M., et al., Interplanetary magnetic field control of dayside auroral activity and the transfer of momentum across the dayside magnetopause, Planet. Space Sci., 37, 1347,1989

Saunders, M.A., et al., Dayside ionospheric convection changes in response to long period IMF oscillations: determination of the ionospheric phase velocity, $J$. Geophys. Res., 97, 19373, 1992.

Sandholt, P.E., et al., Dynamical auroral structure in the polar cusp: multipoint observations during southward and northward IMF, Annales Geophys., 10, 483, 1992.

Todd, H., et al., Response time of the high-latitude dayside ionosphere to sudden changes in the north-south component of the IMF, Planet. Space Sci., 36, 1415, 1988.

S.W.H. Cowley, Blackett Laboratory, Imperial College, London, SW7 2BZ, UK.

V.N. Davda and M. Lockwood, Rutherford Appleton Laboratory, Chilton, Didcot, OX11 0QX, UK.

A.D. Farmer, Atmospheric Physics Laboratory, University College London, W1P 7PP, UK.

U.P. Løvhaug, EISCAT Scientific Association, Ramfjordmoen, N-9027, Ramfjordbotn, Norway

H. Lühr, Institut für Geophysik und Meteorologie, T.U. Braunsweig, W-3300 Braunshweig, Germany

J. Moen, Department of Physics, University of Oslo, Box 1048, Blindern 0316, Oslo 3, Norway.

(Received: February 10, 1993; accepted: March 11, 1993) 